\title{
Breaks in career - What chance for women?
}

\author{
from Richard Pearson
}

\section{Will demographic trends and skill shortages be more effective, at least for women in professional and managerial careers, than the 1960s and 1970s legislation in support of equal opportunities?}

THE proportion of women working or seeking work is now over $48 \%$, and until the recession of the early 1980 s had been steadily growing from a figure of 1 in 10 in 1921. Women now account for $43 \%$ of the labour force in the United Kingdom. While many are concentrated in part-time and low-paid jobs, they form significant and growing proportions of those in teaching, medicine, science and personnel work. They also represent $45 \%$ of those entering higher education. Technological and structural change in the economy have brought about a decline in traditionally male-dominated heavy industry and an expansion in new industrial sectors, such as electronics and services where women are more likely to be found. Likewise, the growth in managerial and highly skilled jobs, and professions such as computing is enhancing women's job prospects, particularly those qualified at graduate level. Demographic trends over the next decade are also likely to lead to an increased participation of women in professional jobs. With the number of 18 year-olds declining by one-third over the next decade, employers are likely to turn increasingly to women in their search for

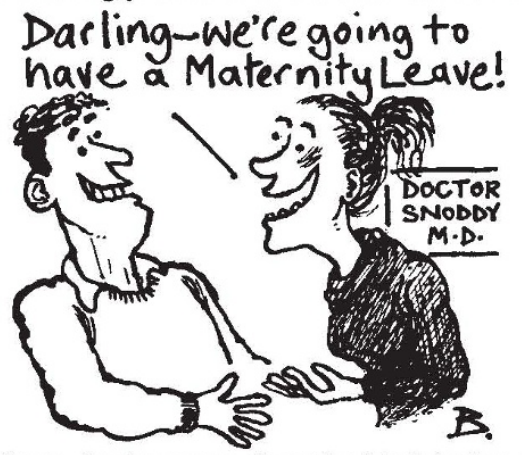

talent. At the same time the birth bulge of the 1950 s and ' 60 s will see increasing numbers of 30-40-year-old women returning to the labour force in the 1990 s.

How then are employers responding to these changes, and in particular what are they doing to help and even encourage women to return to their careers after a period of child-rearing? Those not responding positively may find themselves unable to retain an increasingly important component of their skilled workforce. At a minimum they will be letting go a huge investment in the training and development of employees with valuable and relevant skills.

The Engineering Council are strongly promoting the need for career breaks. A report by the Institute of Manpower Studies ${ }^{1}$ shows, however, that while employers often talk of the costs of policies to help women combine work with a family, very few have measured the costs and lost investment in letting them go.

Although many employers exceed the statutory provision in many areas of employment legislation, they do not tend to do so for maternity leave. As such, the legislative standard tends to be the norm, and most employers and employees seemed to be clear about the provisions of statutory maternity leave, which can last up to 40 weeks. However, individual companies' administrative procedures were less clear, and often poorly handled, with the presumption that the career professional or managerial women should be able to find out everything for themselves.

Data on maternity leave and women leaving from career breaks are also not easy to find, employers often recording women taking normal maternity leave as leavers when they were still technically employees. As a result, some did not know how many were on leave at any one time, which makes monitoring difficult and can inhibit the planning of the women's return to work. The available evidence about the numbers returning suggested that only a small proportion did so, one of the highest being in a computer company where $30 \%$ returned to full-time and $15 \%$ to part-time work.

One major problem in managing the career break in the uncertainty as to the intention to return. There is a legal requirement for a woman to notify her employer of her intention to return, and to reconfirm it 7 weeks after the birth. Most automatically do this to safeguard their job, yet it can inhibit an employer's planning to cover the job and the timing of the subsequent return. One enlightened company has parallel discussions about the real intentions of each individual, without affecting the legal rights, a situation that requires a high degree of trust between the parties. A defeatist attitude to the legislation is clearly avoidable. Given an uncertain duration of leave, various strategies are used to cover the vacant job, including sharing the work out, hiring temps, or in larger organizations likely to have a number of similar jobs, filling it permanently. The latter can, however, cause problems on re-entry if there is not a similar job available at the appropriate time, especially given the generally low levels of managerial turnover in most organizations. Where a woman is not returning to her original job, good practice should include early discussions and counselling as to the options; some women do not know what job they will do until they arrive, adding unnecessary anxiety to an already stressful period.

More women would return if it could be to part-time work, either as a transitional or as a more permanent arrangement. Some employers are able to accommodate this, and there are several computer software companies who operate with high percentages of part-time and often homebased, professional staff. In medicine, doctors have a national scheme which sets a quota of part-time jobs at senior registrar level, and also a retainer scheme which keeps doctors in touch with work if they wish to do very limited hours each week. In traditional organizations, attitudes of peers can be a problem. Thus, the case of a female doctor at consultant level where, in her speciality, work hours could be very flexible. It was quite acceptable for her male colleagues to organize work to allow time to play golf; it was not, however, seen as acceptable that she should organize her hours so as to collect her child from school!

To date, well-organized career breaks for women, let alone men, are still a rarity, yet they represent a missed opportunity for employers and individuals, particularly in the case of highly trained and experienced people. Barriers to change include a low realization of the costs of female wastage, and a failure to plan careers against a longer-term perspective. Resistance to women in management is still strong in many organizations, with a reluctance to accommodate flexible careers and parttime working in professional and managerial jobs. Pressure for a change from women is, however, growing, if slowly, and the more they move into such jobs and become a key source of skilled staff, the more labour market factors and economics will help reduce barriers to change. $\square$

Richard Pearson is at the Institute of Manpower Studies, Mantell Building, University of Sussex, Brighton BN1 9RF, UK.

1. Hirsh, W., Hutt, R. \& Atkinson, J. Women, Career Breaks and Re-entry (Institute of Manpower Studies, Brighton, 1985). 